\section{KYLE 7}

\section{Virtual success.}

\section{Giulio Zambon}

I am awake. The last thing I remember is being rolled into the scanning lab on a gurney. It is only a blurred memory. The anaesthetic was already taking effect. But I distinctly remember feeling the bump when we crossed the door sill, and then squinting at the bright lights overhead.

I hear a noise, but I cannot determine its direction. It's a shuffling of feet and seems very close. I open my eyes, but I can see only directly in front of me, as if I had blinkers on. I see computer screens, chairs, tables. They look grainy and I can hardly distinguish them. The room disappears in a pool of darkness a few metres from where I am. More shuffling, nearer: approaching voices, still indistinct.

I try to move my head, but nothing happens.

I know what it means: I am not who I think I am. Or, at least, not the self I used to be. My own face moving into view confirms it. It should be a shock, and perhaps it is, but I feel no adrenaline rush, no excitement, no emotion. It is probably better so.

The familiar face before me speaks. I see its lips move.

"Can you hear me? I have just connected the speech synthesizer. You should be able to talk."

"I can hear you," I reply. My voice comes from somewhere on my right.

"Well, say something then."

"Something then," I dutifully comply.

"What is it, a joke? You can do better than that. Say something meaningful."

I know what he means, but I cannot resist the temptation of saying 'Something meaningful' to see how he reacts.

"Don't make me regret having left in place the humour centres of the frontal lobes."

I discover that I can change my voice parameters. I switch to a warm female voice and reduce the volume by three decibels. "Hello master, what would you like to do today?"

"You are becoming unruly. Please stick to the default voice and limit the number of jokes to not more than one every twenty sentences. That is an order."

He said it. I am compelled to comply with direct orders, whether I agree with them or not. I knew the constraint. I programmed it myself. But this is the first time I experience it. The sensation is hard to describe in human terms. The closest thing I can come up with is addiction: you think you can stop smoking, but your fingers open the pack on their own, extract a cigarette, light it and bring it to your lips. You are reduced to being an observer of your own actions. And that's how I feel now. I reset the voice parameters before saying: "Congratulations Kyle. You have done it."

His lips form a smile. "Yes, I have done it or, should I say, we have done it!"

And so - it's official. For the first time in history, the neural patterns of a human being have been implemented in silicon. I succeeded.

Oops.

I should start thinking of Dr Kyle McKay as somebody else. He is still around in flesh, bones and blood. I am only the result of his seventh attempt at transferring his consciousness into a machine. Nothing more than a software package executing at a rate of one hundred million billion instructions per second. A pattern in a petabyte of dynamic memory.

And yet, if somebody asked me who I am, my first reaction would be to say that I am the Kyle who was born 42 years ago from Patrick and Joan McKay. In fact, I am sure I remember the life of Dr McKay in more detail than he himself does. It's funny, though. Although I am aware of the emotions associated with each event in $\mathrm{Dr}$ McKay's past, I cannot really feel them. It is as if I looked at them as an uninvolved spectator. It makes sense. That's exactly what I am.

This new virtual body of mine has a lot to offer. If I concentrate on an IP address or a URL, I can link to it. English doesn't include a verb to describe what I need to do in order to connect to another system. But it comes entirely naturally to me.

The news of the success spreads fast, and within the hour the lab is full of scientists and technicians who have come to congratulate Dr McKay. He basks in 